\title{
Long-term effect of vasectomy on spermatogenesis in men: a morphometric study
}

\author{
Yu Xiang ${ }^{1}$, Peng Luo ${ }^{2}$, Yun $\mathrm{Cao}^{2}$ and Zheng-Wei Yang ${ }^{1}$
}

Spermatogenic damage may occur after vasectomy, and the damage is pressure mediated, occurring when the occluded reproductive tract is unable to accommodate additional sperm produced by the testis. This study aimed to determine the long-term effect of vasectomy on spermatogenesis in humans and clarify how the balance between sperm production in the testis and sperm storage in or removal from the tract might be maintained. During inguinal hernia repair, an open biopsy was performed to obtain testicular tissue blocks from 51 Chinese men (aged $\geqslant 50$ years), of whom 25 (control group) had not undergone vasectomy and 26 (vasectomized group) had undergone bilateral vasectomy 22-42 years before. Methacrylate resin-embedded testicular sections were made, and morphometric studies were performed using light microscopy. In addition, sizes of the testis and epididymis were estimated with ultrasonography. The testicular tissue blocks obtained from one control and seven vasectomized men consisted almost completely of connective tissue. In the other $\mathbf{4 3}$ men, significant differences were not found between the two groups in the testicular or epididymal size, qualitative histology or quantitative parameters including the mean diameter or volume fraction of the seminiferous tubules. In conclusion, sperm production and sperm storage/removal reached a static equilibrium after vasectomy, likely due to spermatogenic degeneration or less sperm production as a result of aging or due to vasectomy-induced testicular (interstitial) fibrosis. Thus, complications that might occur in association with overproduction of sperm and distension of the tract would disappear or be relieved with time.

Asian Journal of Andrology (2013) 15, 434-436; doi:10.1038/aja.2012.154; published online 25 February 2013

Keywords: histology; humans; morphometry; spermatogenesis; testis; vasectomy

\section{INTRODUCTION}

Vasectomy is a male contraceptive method involving only one small operation of vasal ligation. It cannot be replaced, in terms of convenience, cost-effectiveness and reliability, by other male contraceptive methods such as hormonal contraception. ${ }^{1}$ Its clinical use, however, is compromised by major concerns about the irreversibility of sterilisation and pressure in the occluded reproductive tract (epididymis and juxta-epididymal vas deferens). While vasectomy reversal or sperm extraction can address the irreversibility, ${ }^{2,3}$ the intra-tract pressure change is inherent with the vasal obstruction of spermatozoa and fluid produced by the testis. The obstruction may result in distension of (or sperm leakage from) the reproductive tract, which may in turn induce local discomfort such as swelling or pain. ${ }^{4,5}$ However, the local effects, if present, may not persist for long because spermatogenic damage and subsequent reduced sperm production will follow when the tract cannot accommodate additional sperm produced. ${ }^{6}$ That is, an equilibrium will be established via a pressure-mediated mechanism between sperm production in the testis and sperm storage in (or sperm removal from) the tract after the operation. ${ }^{6}$ It is unknown whether the spermatogenic damage is sustained and how the balance is maintained in the long term. By examining in-patients aged over 55 years who were without urogenital diseases, we recently found that the sizes (obtained with ultrasonography) of the testes and epididymides in 75 patients with vasectomy (vasal obstructive interval $14-41$ years) were not significantly different from those in 41 patients without vasectomy. ${ }^{7}$ This study was therefore undertaken to evaluate the long-term effect of vasectomy on spermatogenesis in men and clarify how the balance between sperm production and sperm storage/ removal might be maintained without inducing long-term epididymal distension.

\section{MATERIALS AND METHODS}

The subjects included in the study were 51 male patients aged $\geqslant 50$ years with a past history of paternity and no testicular diseases. The subjects were admitted to the People's Hospital of Peng'an County (Peng'an, Nanchong, China) between January 2009 and January 2010 for the surgical treatment of inguinal hernia. Twenty-five patients had not undergone vasectomy, while the other 26 had undergone bilateral vasectomy for contraception 22-42 years before.

The sizes of the testes and epididymides were measured using a high-frequency colour Doppler ultrasound unit. ${ }^{7,8}$ During the inguinal hernia repair, an open biopsy was performed to obtain a testicular tissue block from each patient with written informed consent. Tissue blocks were embedded in methacrylate resin, and three consecutive sections (thickness $25 \mu \mathrm{m}$ ), spaced $125 \mu \mathrm{m}$ apart, were cut from each block and stained with hematoxylin. 
Table 1 Testicular morphometric parameters according to vasectomy status and age (mean \pm s.d., range in parenthesis)

\begin{tabular}{|c|c|c|c|c|}
\hline & \multicolumn{2}{|c|}{ Non-vasectomized men } & \multicolumn{2}{|c|}{ Vasectomized men } \\
\hline & Younger $(n=12)$ & $\operatorname{Older}(n=12)$ & Younger $(n=7)$ & Older $(n=12)$ \\
\hline Age (year) & $54.8 \pm 2.8(50-58)$ & $65.9 \pm 4.6(60-72)$ & $53.6 \pm 2.2(50-57)$ & $64.8 \pm 4.1(60-74)$ \\
\hline Volume of the testis $\left(\mathrm{cm}^{3}\right)$ & $9.6 \pm 2.3(6.9-14.1)$ & $9.6 \pm 2.8(6.3-15.7)$ & $10.6 \pm 3.8(6.4-16.3)$ & $10.3 \pm 2.5(6.6-14.1)$ \\
\hline Volume of the epididymal head and tail $\left(\mathrm{cm}^{3}\right)$ & $0.47 \pm 0.10(0.35-0.69)$ & $0.45 \pm 0.19(0.19-0.88)$ & $0.41 \pm 0.08(0.33-0.51)$ & $0.41 \pm 0.14(0.21-0.65)$ \\
\hline Diameter of the seminiferous tubules $(\mu \mathrm{m})$ & $178 \pm 13(151-199)$ & $183 \pm 16(162-221)$ & $183 \pm 9(171-199)$ & $183 \pm 14(157-201)$ \\
\hline$\%$ of tubule profiles with few late elongated spermatids & $6.3 \pm 4.8(0-14.8)$ & $15.1 \pm 13.9(0-47.4)$ & $8.6 \pm 7.5(0-22.9)$ & $6.9 \pm 6.1(0-18.5)$ \\
\hline $\begin{array}{l}\% \text { of tubule profiles with isolated early round spermatids in } \\
\text { the tubule lumen }\end{array}$ & $6.4 \pm 6.9(0-19.6)$ & $6.6 \pm 7.8(0-20.0)$ & $6.1 \pm 3.9(0-11.1)$ & $5.9 \pm 4.6(0-14.3)$ \\
\hline
\end{tabular}

The results were from 43 men from whom testicular tissue blocks consisting mainly of seminiferous tubules were obtained. $P>0.05$ for each parameter not including the age or vasal obstructive interval (two-way analysis of variance for comparison between the four subgroups of men): vasectomy (factor 1) or age (factor 2) had no significant effect, and there was no significant interaction between vasectomy and age.

Sections were observed on a computer screen equipped with a stereology image system. The volume fraction of the seminiferous tubules in the testis, the diameter of the tubules, the thickness of the basement membrane covering the tubules and the percentage of tubules with certain morphological characteristics (Table 1) were estimated with morphometric (stereological) methods as we previously described. ${ }^{6,8}$

\section{RESULTS}

In $1(4.0 \%)$ of non-vasectomized and $7(26.9 \%)$ of vasectomized (obstructive interval 28-42 years) men (with testicular sizes comparable to other men), few seminiferous tubule profiles were observed in the sections, i.e., the tissue blocks consisted almost completely of connective tissue. (Fisher exact test for a comparison between the two proportions: $P<0.05$.) Data from these eight men are not included in Table 1.

In the other 43 men, no quantitative parameters (not including vasal obstructive interval) were significantly correlated to age (Pearson product moment correlation: $r=0.00-0.17, P>0.28$ ) (Table 1). In the 19 vasectomized men, no quantitative parameters (not including age) were significantly correlated with the obstructive interval $(r=-0.16-0.17$, $P>0.36$ ). Testicular histology (qualitative observation) did not appear to differ between the 24 non-vasectomized men (age 50-72 years) and the 19 vasectomized men (age 50-74 years, obstructive interval 22-39 years). None of the evaluated parameters (not including age or obstructive interval) significantly differed between these two groups (vasectomized and non-vasectomized) of men ( $t$-test: $P>0.13$ ) (Table 1); a similar conclusion was reached (two-way analysis of variance for each parameter: $P>0.05$ ) when each group of men was further divided into two subgroups by age: age 50-58 years and age 60-74 years (Table 1).

\section{DISCUSSION}

Spermatogenic damage may occur after vasectomy. One month after vasectomy, the damage may be severe, ${ }^{9}$ and at $1-20$ years after the procedure, a $20 \%-40 \%$ reduction in the numbers of spermatids may exist. ${ }^{10}$ As demonstrated in the current study, however, vasectomy did not induce marked long-term spermatogenic damage at 22-39 years postoperation in the 19 vasectomized men (Table 1). This suggests that, in older men long after vasectomy, sperm may no longer be overproduced, or sperm production and sperm storage/removal may reach a static equilibrium without considerable intra-tract pressure to damage spermatogenesis in the testis. ${ }^{6}$ It has also been suggested that vasectomy-induced complications that might occur in association with overproduction of sperm and distension of the tract would therefore disappear or be relieved in the long term. As previously reported, the daily sperm production (testis) or total sperm count (semen) is reduced by more than $30 \%$ in older men aged $50-80$ years (compared with younger men aged $20-50$ years). ${ }^{11-14}$ Thus, the aging (degenerative) effect on spermatogenesis or sperm production may be the primary contributor to the static equilibrium.

It is difficult to explain why a larger proportion of fibrotic tissue blocks (with few seminiferous tubules) were obtained at the time of testicular biopsy in vasectomized men than non-vasectomized men. If not by chance, it might indicate testicular (interstitial) fibrosis after vasectomy. ${ }^{10,15-17}$ In this case, vasectomy did have some long-term effects on spermatogenesis. Nonetheless, this would not affect the conclusion that complications such as epididymal distension and sperm granuloma, which might result from continual sperm production after vasectomy, ${ }^{4,5}$ would not become increasingly severe in older men or in the long term.

\section{AUTHOR CONTRIBUTIONS}

YX prepared, observed and measured the sections; PL and YC obtained the samples and clinical data; and ZWY designed the study, embedded the tissue blocks, performed the statistical analysis and wrote the manuscript.

\section{COMPETING FINANCIAL INTERESTS}

The authors declare no competing financial interests.

\section{ACKNOWLEDGMENTS}

This study was supported by grants from the Sichuan Department of Health (No. 060215) and Nanchong Bureau of Science and Technology (N2007SF010).

1 Mahmoud A, T'Sjoen G. Male hormonal contraception: where do we stand? Eur J Contracept Reprod Health Care 2012; 17: 179-86.

2 Tournaye $\mathrm{H}$. Update on surgical sperm recovery - the European view. Hum Fertil 2010; 13: 242-6.

3 Schwarzer JU. Vasectomy reversal using a microsurgical three-layer technique: one surgeon's experience over 18 years with 1300 patients. Int J Androl 2012; 35: 70613.

4 McDonald SW. Is vasectomy harmful to health? Br J Gen Pract 1997; 47: 381-6.

5 Magheli A, Schulze W, Weiske WH, Kempkensteffen C, Miller K et al. [Evaluation of obstructive interval, presence of sperm granulomas and patient age as predictors of spermatogenesis in a cohort of men undergoing vasectomy reversal.] Aktuelle Urol 2010; 41: 52-7 
6 Peng B, Mao Y, Tang XF, Shang Y, Shen CY et al. Comparison of spermatogenic damage induced at 6 months after ligation of the vas deferens at proximal and distal locations in the rabbit. Andrologia 2011; 43: 129-38.

7 Zhang TS, Luo P, Li JY, Lu XF, Yu XB et al. [Long-term effect of vasectomy on the sizes of the epididymis, testis and prostate: an ultrasonographic study.] J North Sichuan Med College 2010; 25: 443-5.

8 Yang ZW. [Practical Stereological Methods: Essential Tools for Morphometric Studies of Biological Tissues.] Beijing: Science Press; 2012. pp84-6, 90-3, 127-8, 140. [in Chinese]

9 Gupta AS, Kothari LK, Dhruva A, Bapna R. Surgical sterilization by vasectomy and its effect on the structure and function of the testis in man. Br J Surg 1975; 62: 59-63.

10 Raleigh D, O'Donnell L, Southwick GJ, de Kretser DM, McLachlan RI. Stereological analysis of the human testis after vasectomy indicates impairment of spermatogenic efficiency with increasing obstructive interval. Fertil Steril 2004; 81: 1595-603.

11 Johnson L, Petty CS, Neaves WB. Influence of age on sperm production and testicular weights in men. J Reprod Fertil 1984; 70: 211-8.
12 Eskenazi B, Wyrobek AJ, Sloter E, Kidd SA, Moore L et al. The association of age and semen quality in healthy men. Hum Reprod 2003; 18: 447-54.

13 Zavos PM, Kaskar K, Correa JR, Sikka SC. Seminal characteristics and sexual behavior in men of different age groups: is there an aging effect? Asian J Andro/ 2006; 8: 337-41.

14 Molina RI, Martini AC, Tissera A, Olmedo J, Senestrari D et al. Semen quality and aging: analysis of 9168 samples in Cordoba, Argentina. Arch Esp Urol 2010; 63: 214-22.

15 Mehrotra R, Nath P, Tandon P, Singh KM, Kumar H. Ultrastructural appearances of interstitial tissue of testis in vasectomised individuals. Indian J Med Res 1983; 77: 347-52.

16 Jarow JP, Budin RE, Dym M, Zirkin BR, Noren S et al. Quantitative pathologic changes in the human testis after vasectomy. A controlled study. N Engl J Med 1985; 313. 1252-6.

17 Shiraishi K, Takihara H, Naito K. Influence of interstitial fibrosis on spermatogenesis after vasectomy and vasovasostomy. Contraception 2002; 65: 245-9. 